\title{
Sistematização da Assistência de Enfermagem: acidente por Loxosceles gaucho
}

\author{
Nursing Care Sistematization: accident by Loxosceles gaucho \\ Sistematización de la Asistencia de Enfermería: accidente por Loxosceles gaucho
}

\section{Helayne Mika Kamimura', Bianca Sakamoto Ribeiro Paiva', Jairo Aparecido Ayres'}

'Universidade Estadual Paulista. Curso de Enfermagem da Faculdade de Medicina de Botucatu. Botucatu, SP

Submissão: 05/09/2008

Aprovação: 20/10/2009

\section{RESUMO}

Relato de experiência realizado em um hospital de ensino, com uma paciente vítima de acidente por aranha do gênero Loxosceles gaucho. Este tipo de acidente pode ser classificado como leve, moderado e grave, o que dependerá do tempo entre o ocorrido e o atendimento. Objetivou-se aplicar a sistematização da assistência de enfermagem de forma integralizada e humanizada. Foram estabelecidos os seguintes diagnósticos de enfermagem: dor aguda, integridade da pele prejudicada, riscos para infecção, constipação e baixa auto-estima. $\mathrm{O}$ relacionamento terapêutico favoreceu as interações aluna/paciente e possibilitou o reconhecimento das necessidades Que mereciam intervenções de enfermagem. O processo de enfermagem foi um instrumento valioso e trouxe elementos importantes para a evolução diária da paciente e adeeuação do planejamento, priorizando a Qualidade dos cuidados.

Descritores: Aracnidismo; Diagnóstico de enfermagem; Processos de enfermagem; Assistência de enfermagem.

\begin{abstract}
Experience report carried out at a university hospital involving a patient victimized by an accident with a spider of the Loxosceles gaucho genus. This type of accident can be classified as mild, moderate and severe, depending on the period of time elapsed between the occurrence of the accident and the moment of care provision. We aimed at applying nursing care systematization in a comprehensive and humanized manner. The following nursing diagnoses were established: acute pain, damaged skin integrity, risks for infection, constipation and low selfesteem. The therapeutic relationship favored student/patient interactions and enabled the recognition of the needs that deserved nursing interventions. The nursing process was a valuable instrument and provided important elements for the patient's daily development and planning adjustment by prioritizing care Quality.
\end{abstract}

Descriptors: Arachnidism; Nursing diagnosis; Nursing process; Nursing care.

\section{Resumen}

Relato de experiencia realizado en un hospital de enseñanza, con una paciente víctima de accidente causado por araña del género Loxosceles gaucho. Este accidente puede ser clasificado como leve, moderado o grave, lo que dependerá del tiempo entre el suceso y la atención. Se pretendió aplicar la sistematización de la asistencia de enfermería de forma integral y humanizada. Se establecieron los siguientes diagnósticos de enfermería: dolor agudo, integridad de la piel perjudicada, riesgos de infección, constipación y baja autoestima; la relación terapéutica favoreció las interacciones alumna/paciente y posibilitó el reconocimiento de las necesidades Que merecían intervenciones de enfermería. El proceso de enfermería fue un instrumento valioso y trajo elementos importantes para la evolución diaria de la paciente y adecuación de la planificación, lo Que prioriza la calidad de los cuidados.

Descriptores: Aracnidismo; Diagnóstico de enfermería; Procesos de enfermería; Atención de enfermería. 


\section{INTRODUÇÃO}

Por Questão de sobrevivência vários animais migram de seu ambiente natural para os centros urbanos e domésticos, a partir daí a ocorrência de acidentes por animais peçonhentos se torna mais freqüente em conseqüência do desequilíbrio ecológico.

Entre os artrópodes as aranhas constituem a ordem mais ampla com hábitos solitários. São comumente encontradas em ambientes domiciliares e peridomiciliares o Que amplifica a probabilidade de acidentes com seres humanos ${ }^{(1)}$.

No Brasil existem três gêneros de aranhas que causam danos ao homem: Phoneutria, Lactodectrus, Loxoceles. Neste estudo daremos ênfase à descrição de um caso provocado pelo gênero Loxoceles Que é conhecido popularmente como a aranha-marrom ${ }^{(1)}$.

O loxoscelismo corresponde a $36,6 \%$ dos casos no Brasil, sendo Que a maioria dos casos concentra-se na região Sul, principalmente no Paraná e Santa Catarina, a incidência de acidente chega a 5000 casos notificados por ano, nas regiões Sul e Sudeste ${ }^{(2)}$.

Recomenda-se manter a casa limpa e a área ao seu redor; evitar depósito de lixo e entulhos; manter limpos armários e outros ambientes escuros e úmidos, com a finalidade de prevenir Que animais peçonhentos utilizem estes ambientes como abrigo, além de observar roupas e sapatos criteriosamente antes de usá-los, vedar buracos em muros e vãos de portas ${ }^{(3)}$.

Estes artrópodes não são agressivos, porém picam Quando se sentem ameaçados ou Quando são comprimidos contra a pele, mais especificamente no caso da aranha marrom.

O veneno da Loxosceles possui atividade hemolítica e dermonecrótica, Que parecem ser causadas pela esfingnomielinase-D. A picada é praticamente imperceptível e raramente se evidencia lesão imediata. Inicialmente, a picada causa dor de pequena intensidade passando praticamente imperceptível pela vítima, lembram picada de inseto e evolui lentamente. A ação do veneno pode produzir lesões tanto cutâneas Quanto cutâneovisceral ${ }^{(1)}$.

A evolução é caracterizada pela intensificação da dor, aparecimento de isquemia, vasoespasmo, formigamento, eritema e edema, progredindo para uma lesão com áreas irregulares posteriormente evoluindo para placas enduradas e escuras, dando origem a uma úlcera necrótica com diâmetros diferenciados. Podendo ocorrer o aparecimento de bolhas com conteúdo seroso ou hemorrágico, e vesículas de aspecto herpetiforme ${ }^{(4)}$.

A lesão ulcerada sofre processo de granulação lento, em geral a cicatrização pode demorar meses, em alguns casos necessita de cirurgia reparadora ${ }^{(4)}$

Destaca-se a importância de uma avaliação detalhada da lesão pelo enfermeiro Que deve atentar-se para os sinais e sintomas locais de inflamação, o aparecimento de secreções, tecido desvitalizado e necrose.

Com base nas especificidades deste tipo de acidente o objetivo do relato foi enforcar a importância do planejamento da assistência de enfermagem.

\section{MÉTODO}

Este relato foi realizado em um hospital de ensino do interior paulista durante o estágio supervisionado de enfermagem em doenças transmissíveis.
Utilizamos o modelo assistencial de Horta ao processo de Sistematização da Assistência de Enfermagem (SAE), conjuntamente com a Taxonomia II dos Diagnósticos de Enfermagem da North American Nursing Diagnosis Association (NANDA) ${ }^{(5)}$. O método possibilitou o relacionamento terapêutico da aluna/paciente durante os cuidados de enfermagem em suas necessidades.

\section{RESULTADOS E DISCUSSÃO}

O método aplicado à assistência de enfermagem consistiu de um plano sistematizado, Que dinamizou as etapas Que compõem o processo de enfermagem, promovendo um cuidado de Qualidade, possibilitando ainda, um aprendizado nas diferentes situações com reflexão da prática do enfermeiro ${ }^{(5,6)}$.

Além disso, teve como foco o indivíduo e as suas respostas perante os problemas de saúde durante a internação o Que contribuiu para o desenvolvimento do autocuidado. Partindo deste principio é possível afirmar Que processo contribui nas decisões Que envolvem enfermeiro/paciente ${ }^{(7)}$. A seguir apresentaremos alguns aspectos Que envolveram o acidente e as intervenções de enfermagem.

Durante as interações foi possível evidenciar a evolução da lesão com presença de hemorragias focais, mescladas com áreas isQuêmicas e necróticas, acompanhadas de dor, edema e eritema, caracterizando o comprometimento cutâneo e subcutâneo. Devido à ação hemolítica do veneno ocorre hemólise intravascular, desencadeando anemia, icterícia e hemoglobinúria, geralmente nas primeiras 24 horas, podendo evoluir para a insuficiência renal aguda $^{(4)}$. Este tipo de complicação não foi evidenciado no caso em Questão, sendo este classificado como moderado, restringindo-se a lesões típicas.

Geralmente, o tratamento consiste na hidratação, soro antiloxosceles, analgésicos e agentes tópicos. Neste caso, limitouse aos analgésicos e agentes tópicos, uma vez Que a soroterapia não tinha indicação, pois excedeu o tempo de 36 horas passando este período não há indicação. Tal situação pode ser explicada pela impercepção do acidente Que, inicialmente, não causa dor e tem uma evolução lenta e progressiva. No caso da dor, esta se acentua, entre 24 a 72 horas, o que desencadeará sinais e sintomas os Quais justificam a procura pelos serviços de saúde ${ }^{(1)}$.

No presente relato, a paciente referiu Que não interrompeu suas atividades diárias e não deu importância alterações locais, o Que contribuiu para o desenvolvimento do Quadro infeccioso.

A situação exigiu hospitalização necessitando de desbridamento mecânico Que auxiliou na cicatrização, sendo este procedimento realizado pelo enfermeiro. O processo de desbridamento consistiu na remoção do tecido desvitalizado e da área necrosada expondo o tecido saudável. Isso proporcionou uma maior irrigação tecidual acelerando o processo de granulação celular e conseqüentemente a cicatrização ${ }^{(8)}$. Além do desbridamento mecânico foi indicado o Químico com uso de papaína a 10\% e antibioticoterapia sistêmica profilática $^{(9)}$.

O antibiótico indicado predispõe a alterações cardiovasculares, hidroeletrolíticas e gastrointestinais, estas não foram detectadas, porém houve uma irritação no trajeto venoso com aumento da temperatura, seguido de dor, Que foi associado ao antibiótico e a permanência do dispositivo venoso ${ }^{(9)}$. Essa medida levou a regressão do processo infeccioso da lesão, porém, com uma evolução 
fibrinótica e necrose tecidual, havendo a necessidade de realizar o curativo e o desbridamento com maior freqüência, objetivando acelerar a cicatrização.

\section{Histórico da paciente}

Paciente do sexo feminino, 67 anos, procedente de uma cidade do interior paulista, branca, casada, católica, com atividades no lar, em tratamento para hipertensão e depressão. Referiu Que havia sido picada por uma aranha não dando importância, pois a dor era insignificante.

Ao exame físico apresentava-se orientada, com mucosas coradas e hidratadas, referindo dor intensa no local da lesão. Em relação ao exame cardiopulmonar e demais segmentos corporais, incluindo as necessidades fisiológicas, não foram expressas e nem detectada nenhuma alteração. Com acesso venoso em membro superior para medicação intermitente apresentando sinais de irritação local. Com uma lesão no pé direito Que se estendia do dorso até o $2^{\circ}$ pododáctilo e tecidos adjacentes, compatíveis com a ação gravitacional do veneno, com aumento da temperatura, edema discreto, secreção serosa, fibrina e áreas de necrose.

\section{Diagnósticos e Intervenções de Enfermagem}

Os diagnósticos foram descritos segundo a NANDA ${ }^{(5)}$ atendendo às necessidades da paciente, visando um atendimento integralizado e humanizado.

- Dor aguda caracterizada por relato verbal, expressão facial, distúrbios do sono, respostas autonômicas como alteração da pressão sangüínea e comportamento expressivo relacionado à lesão no pé.

- Conduta: O enfermeiro deve proporcionar um ambiente terapêutico, avaliar a intensidade e freqüência da dor, manter o membro em uma posição confortável, conseQüentemente haverá alívio da dor e melhora da irrigação sanguínea. Além disso, deve oferecer apoio e compreensão, discutir sobre as alternativas de melhor posicionamento do membro, aplicar compressas frias, analgésicos Quando necessário e previamente aos curativos. É importante frisar Que o paciente deve ser co-participante de seus cuidados.

- Integridade da pele prejudicada caracterizada por destruição de camadas da mesma relacionada ao acidente com aranha e ação do veneno.

Foi possível diagnosticar esta alteração, pois a pele oferece proteção Quando íntegra, assim mantê-la nesta condição é fundamental, para Que o organismo consiga impedir interferências externas $^{(5)}$.

A integralidade da pele prejudicada é um diagnóstico real tendo como característica definidora à invasão da estrutura do corpo, neste caso, a picada da aranha, com a introdução do veneno favoreceu a destruição tecidual e posterior processo infeccioso.

- Conduta: Proporcionar condições de higiene corporal criteriosa e realizar curativo sendo a freqüência definida de acordo com os agentes tópicos utilizados. Inicialmente foi aplicado antibiótico tópico sem êxito, substituindo por papaína a 10\% com curativos a cada 24 horas. A papaína é uma enzima proteolítica de origem vegetal Que tem ação desbridante, antiinflamatória, bactericida e bacteriostática, reduz a formação de Quelóides devido sua ação aceleradora e modeladora do tecido de granulação e dos processos de cicatrização tecidual ${ }^{(10)}$. O resultado foi satisfatório visto Que houve o desbridamento Químico da lesão, com renovação celular e posterior cicatrização.

- Risco para infecção relacionado à presença de dispositivo venoso e internação hospitalar.

- Conduta: Por este diagnóstico é importante observar o local de inserção do dispositivo venoso a fim de detectar sinais flogísticos. Promover a troca do mesmo seguindo as recomendações da Comissão de Infecção Hospitalar local, atentando-se para as Queixas do paciente. Para evitar a ação irritante dos antibióticos, é recomendável, diluir os mesmos, em um maior volume (50 a 100ml) o Que poderá diminuir a agressão aos vasos e outros efeitos indesejáveis Quando administrados em bolus ${ }^{(1)}$.

O ambiente hospitalar predispõe ao risco de infecção, devido à diversidade de agentes infecciosos e aos procedimentos invasivos. Os dispositivos utilizados por tempo prolongado, tais como os cateteres (no caso os endovenosos), podem ser porta de entrada para os microorganismos, assim como as falhas na técnica de inserção dos mesmos e a falta de controle do tempo de permanência, estes são fatores Que contribuem para a infecção. Ressaltando Que o próprio cateter trata-se de um corpo estranho Que também pode levar as alterações locais ${ }^{(12)}$.

- Risco para constipação relacionado à mudança de ambiente, de padrões habituais de alimentação e uso de antidepressivos.

- Conduta: O enfermeiro, ao realizar o exame físico, deve atentarse para as Questões relacionadas ao funcionamento do trânsito intestinal, certificando-se da presença dos ruídos hidroaéreos, tendo também como referencial a eliminação de flatos, freqüência e características das evacuações. Com estes dados poderá avaliar e aplicar seus conhecimentos para preservar ou melhorar a função intestinal e Quando houver necessidade, solicitar avaliação do profissional da área. Além de monitorizar a ingesta alimentar e as eliminações diariamente.

Dentre as causas Que podem desencadear a constipação intestinal encontra-se a hospitalização, tendo como fatores a imobilização no leito, a restrição hídrica e efeitos colaterais de alguns medicamentos $^{(13)}$

- Risco para baixa auto-estima situacional relacionado à mudança do papel social (internação) e alteração física.

- Conduta: É importante intensificar a comunicação estimulando a verbalização de seus sentimentos, envolvê-la nas tomadas de decisões para combater a ambivalência e a procrastinação associadas à baixa auto-estima; promover momentos de lazer como leitura, vídeos, jogos, banho de sol e interação com outros pacientes ${ }^{(14)}$.

\section{CONSIDERAÇÕES FINAIS}

O processo de enfermagem possibilitou uma maior interação com a paciente e o conhecimento das implicações do acidente aracnídeo, o que facilitou o planejamento da assistência de forma integralizada.

Foi um importante instrumento da prática assistencial uma vez Que direcionou o cuidado individualizado atendendo as necessidades da paciente, assim como, uma avaliação posterior da evolução do caso. Conseqüentemente, trouxe argumentos importantes para a adeeuação do plano assistencial e o aprendizado teórico-prático nos diversos segmentos do processo saúde-doença, baseando-se 
em dados científicos.

Cabe também ao enfermeiro o papel educativo no Que tange ao esclarecimento da população Quanto a este tipo de acidente, prevenindo o contato com este artrópode por meio de medidas higiênicas no ambiente doméstico. Assim como, a observação das vestimentas antes de usá-las, pois é comum encontrá-lo em objetos de uso pessoal. Na ocorrência deste tipo de acidente, após a identificação ou a suspeita do artrópode, deverá procurar atendimento imediato, pois com o passar do tempo a ação do veneno é intensificada levando a destruição dos tecidos com alterações sistêmicas. Portanto, Quando o tratamento específico for instituído precocemente evitará a hospitalização e complicações.

\section{REFERÊNCIAS}

1. Cupo P, Azevedo-Marques MM, Hering SE. Acidentes por animais peçonhentos: escorpiões e aranhas. Medicina 2003; 36: 490-7.

2. Frezza RM. Atendimento fisioterapêutico após cirurgia reparadora de lesões por aranha marrom: relato de caso. Rev Bras Prom Saúde 2007; 20(2): 133-40.

3. Ministério da Saúde (BR). Manual de diagnóstico e tratamento de acidentes por animais peçonhentos. $2^{\mathrm{a}}$ ed. Brasília: Fundação Nacional de Saúde; 2001.

4. Barbaro KC, Cardoso JLC. Mecanismo de ação do veneno de Loxosceles e aspectos clínicos do Loxoscelismo. In: Cardoso ILC, França FOS, Fan FW, Malaque CM, Haddad Jr. V. Animais peçonhentos no Brasil. Biologia, clínica e terapêutica dos acidentes. São Paulo: Sarvier; 2003. p. 160-74.

5. North American Nursing Diagnosis Association. Diagnósticos de Enfermagem da NANDA: definições e classificação 20082009. Porto Alegre: Artmed, 2007.

6. Hermida PMV, Araújo IEM. Sistematização da assistência de enfermagem: subsídios para implantação. Rev Bras Enferm 2006; 59(5): 675-9.

7. Feijão AR, Carvalho MF, Carmo FT. Avaliação da sistematização da assistência de enfermagem em hospital de doenças infecciosas. Online Braz I Nurs 2006; 5(2): 1-10.

8. Smeltzer SC, Bare BG. Brunner \& Suddarth. Tratado de Enfermagem Médico-Cirúrgica. 10 $0^{\mathrm{a} e d}$. Rio de Janeiro: Guanabara Koogan; 2006.

9. Durrheim D, Barnett FI. Necrotic arachnidism: dispelling fact with fiction. Lancet 2004; 364 (9450): 2018-9.

10. Jorge SA, Dantas SRPE. Abordagem multiprofissional do tratamento de feridas. São Paulo: Atheneu; 2003.

I1. Potter PA, Perry AG. Administração de medicamentos. In: Porter PA, Perry AG. Fundamentos de enfermagem. $4^{\mathrm{a}}$ ed. Rio de Janeiro: Guanabara Koogan; 1999. p. 72 I-96.

12. Garner JS, Jarvis WR, Emori TG, Horan TC, Hughes JH. CDC definitions for nosocomial infections. Am I Infect Control 1998; 16: 128-40.

13. Hickey IV. The clinical practice of neurological and neurosurgical nursing. $5^{\text {th }}$ ed. Philadelphia: Lippincott Williams \& Wilkins; 1999

14. Ralph SS, Taylor CN. Manual de diagnóstico de enfermagem. $6^{\mathrm{a}}$ ed. Rio de Janeiro: Guanabara Koogan; 2007. 